\title{
Role of the Retinoblastoma Gene in the Initiation and Progression of Human Cancer
}

William F. Benedict, Hong-Ji Xu, Shi-Xue Hu, and Rei Takahashi

Center for Biotechnology, Baylor College of Medicine, The Woodlands, Texas 77381

Retinoblastoma, although the most common malignant ocular tumor in childhood, is still a rare human malignancy. Nevertheless, the characterization of the molecular steps involved in the development of this cancer and the isolation of the gene responsible for tumor initiation have provided fundamentally important knowledge regarding a class of human cancer genes which have been defined as tumor "suppressor" or "regulatory" genes by us (1) and "antioncogenes" by others (2). Whatever the terminology one wishes to use, the more important issue is that the retinoblastoma $(\mathrm{Rb})^{1}$ gene is representative of a class of cancer genes in which the functional loss of both alleles is critical for tumor formation. In addition, recent evidence suggests that the loss of $\mathrm{Rb}$ gene function is not only causally related to the development of retinoblastoma and tumors that occur as second cancers in patients with the hereditary form of retinoblastoma, but also is a key factor in the initiation and/or progression of several of the most common human malignancies including those of lung, breast, and bladder.

As early as 1971 it was postulated that two "mutational" changes were sufficient for the development of retinoblastoma (3). This hypothesis was based primarily upon statistical data indicating that individuals with the hereditary form of retinoblastoma developed tumors earlier than those with nonhereditary disease (3). It was also known that a small portion of individuals with the hereditary form of retinoblastoma had a deletion within chromosome 13 in their constitutional cells, but only in the late 1970s was the common region of deletion in these patients localized to 13 q14 by high-resolution chromosome mapping (4). It was not until 1983, however, that data were obtained to enable the conclusion to be reached that the same $\mathrm{Rb}$ locus was likely responsible for all forms of retinoblastoma (5).

During the time these studies were ongoing, other findings at both the cytogenetic and molecular biological level strongly suggested that the loss of both $\mathrm{Rb}$ alleles was responsible for tumor formation $(1,6-9)$. This included the fact that there

Address reprint requests to Dr. Benedict, Center for Biotechnology, Baylor College of Medicine, 4000 Research Forest Drive, The Woodlands, TX 77381.

Received for publication 1 December 1989 and in revised form 10 January 1990.

1. Abbreviations used in this paper: $\mathrm{Rb}$, retinoblastoma; RFLP, restriction fragment length polymorphism; SCLC, small cell lung carcinoma.

J. Clin. Invest.

(C) The American Society for Clinical Investigation, Inc.

0021-9738/90/04/0988/06 \$2.00

Volume 85, April 1990, 988-993 were a significant number of $\mathrm{Rb}$ patients who did not have the hereditary deletion form of the disease but in whom a total loss of a 13 chromosome or a deletion including chromosomal region $13 q 14$ was documented in their tumors $(6,7)$. In addition, highly significant studies using restriction fragment length polymorphisms (RFLPs) located on chromosome 13 indicated that there was a loss of heterozygosity for chromosome 13 in these tumors whether or not there was a loss of a chromosome 13 discernible by cytogenetic analysis $(8,9)$. Following up on these initial findings, it was possible to show that as many as $75 \%$ of the cases in which we were not able to identify chromosome 13 abnormalities in their tumors became homozygous for a portion of chromosome 13 when compared to the heterozygous state of these same chromosome 13 fragments in their constitutional cells (10). Consequently, the second "mutational" event previously postulated as being involved in the development of retinoblastoma (3) appeared to be a gross abnormality of chromosome 13 including loss of the entire 13 chromosome or a mitotic recombination resulting in the loss of the normal $\mathrm{Rb}$ allele rather than being a point or frameshift mutation.

Individuals who inherit a mutated $\mathrm{Rb}$ allele also develop a significant number of second malignancies of which osteosarcomas and soft tissue sarcomas are the most frequent (11). After the cloning of the putative Rb gene (12-14), the functional loss of the $\mathrm{Rb}$ gene was reported in a number of osteosarcomas $(12,14,15-18)$ and certain soft tissue sarcomas (16, 19, 20). Moreover, similar changes have been found in tumors such as adenocarcinoma of the breast (21-22), small cell lung carcinoma (SCLC) $(23,24)$ and bladder carcinoma (25). These later malignancies are not usually associated with a previous history of retinoblastoma, although a higher incidence of lung and bladder cancer has been suggested to occur in relatives of retinoblastoma patients who carried the $R b$ mutation or in possible Rb carriers (26). Nevertheless, it is unlikely that the loss of the $\mathrm{Rb}$ gene is sufficient for tumor development in any of these tumors with the exception perhaps of retinoblastoma. Consequently, one of the critical questions still remaining is whether the changes reported within the $\mathrm{Rb}$ gene in different cancers are causally related to the initiation of the tumor or whether they are involved in tumor progression. Therefore, one of the primary goals of this review article will be to discuss not only the abnormalities observed within the $\mathrm{Rb}$ gene in retinoblastoma and the tumor types that often occur as second malignancies in patients with hereditary retinoblastoma, but also to comment upon the possible importance of $\mathrm{Rb}$ gene loss in other common human cancers. Since we believe it could be of fundamental importance at both the basic and clinical level to know whether the loss of $\mathrm{Rb}$ function is associated with the initiation rather than the progression of a specific tumor, the 
use of immunohistochemical staining to distinguish between these two possibilities will be another major focus.

\section{$R b$ gene abnormalities in retinoblastoma and second malignancies}

The initial report of a total structural loss within a DNA sequence located near the Rb locus used a DNA probe, H3-8, (27) which had been obtained from a chromosome 13 library and mapped to the same region as the Rb gene, namely $13 q 14$. Two retinoblastomas were identified that were missing genetic sequences corresponding to the H3-8 probe (28). These results provided important evidence that not only was the loss of genetic material likely to be involved in retinoblastoma development but also suggested that the H3-8 DNA sequence was near or could even be within the Rb gene itself. In fact, the H3-8 probe has been used as the initial starting point for all three groups who were successful in cloning the putative $\mathbf{R b}$ gene (12-14). Each group used chromosomal walking techniques to identify a cDNA sequence coding for a $4.7-\mathrm{kb}$ mRNA which represented the Rb transcript (12-14).

After the cDNA for the putative Rb gene was obtained, it was divided into a 3.8 - and $0.9-\mathrm{kb}$ probe which identified the $3^{\prime}$ and $5^{\prime}$ portions of the Rb gene as well as its transcript (12-14). In the first report on the cloning of the putative $\mathrm{Rb}$ gene, retinoblastomas were described which either were missing all the $\mathbf{R b}$ exon fragments or the $\mathbf{3}^{\prime}$ portion of the putative $\mathbf{R b}$ gene (12). In addition, a case of a possible hemizygous internal deletion of one $\mathrm{Rb}$ allele was presented (12). Another group of researchers noted several retinoblastomas which had no $R b$ transcript or a truncated transcript, although they found no gross structural abnormalities in the Rb gene using the probes that were available (13). In our initial report of the cloning of the putative $\mathrm{Rb}$ gene, we were able to document two cases of retinoblastoma which had homozygous internal deletions within the gene indicating that the gene which had been isolated was indeed the authentic Rb gene (14). In this study 16 of 40 retinoblastomas were found to have structural changes within the $\mathrm{Rb}$ gene, and among those tumors without detectable structural changes there was either an absence or truncation of the Rb transcript (14). Subsequently, point mutations of the $\mathrm{Rb}$ gene in retinoblastomas have been found using different techniques including amplification of specific portions of the $\mathrm{Rb}$ gene followed by DNA sequencing of this amplified region $(29,30)$ or by the use of the ribonuclease protection assay (31).

The $\mathrm{Rb}$ gene also has been transferred into an $\mathrm{Rb}$-negative retinoblastoma cell line (WERI-27) by infection of a defective retrovirus containing the full-length $\mathrm{Rb} \mathrm{cDNA}$ insert. The recipient retinoblastoma cells were subsequently shown to produce a normal $\mathrm{Rb}$ protein with a concomitant decrease in growth rate of the cultured cells to approximately one-third that of WERI-27 cells which were infected with the retrovirus which did not contain the Rb cDNA (32). In addition, 4 wk after infection cells appeared which were enlarged and these cells increased in number over the next 4 wk (32). The enlarged cells disappeared during the subsequent 2 or 4 wk in culture which was correlated with a loss of detectable Rb protein and an increased growth rate in the mass population (32). These results suggested that a restoration of the $\mathrm{Rb}$ protein produced morphological changes and significantly inhibited cell growth. We have also recently observed that the transfer of a normal chromosome 13 by microcell fusion into the retinoblastoma cell line, Y-79, resulted in the production of normal $\mathrm{Rb}$ protein, the appearance of enlarged cells, and the inhibition of growth rate to a marked extent (Benedict, W. F., A. Banerjee, E. J. Stanbridge, S.-X. Hu, H. J. Xu, manuscript submitted for publication). Finally, Rb-positive WERI-27 cells were nontumorigenic when injected into nude mice compared to their Rb-negative parental cells which provided formal proof that the cloned gene was the actual Rb gene (32). We also found that $\mathrm{Rb}$-positive $\mathrm{Y}-79$ were nontumorigenic in nude mice (Benedict et al., manuscript submitted for publication).

Since osteosarcomas are the most common second malignancies seen in patients with the hereditary form of retinoblastoma, it was logical to look for chromosome 13 changes in these tumors as well. The first paper to study this possibility used RFLPs located on chromosome 13 to examine whether a reduction to homozygosity occurred for chromosome 13 in osteosarcoma as had been seen in retinoblastoma. It was found that indeed there was a change from heterozygosity in constitutional cells to homozygosity in the osteosarcomas for several chromosome 13 DNA fragments, whether or not the tumors developed in patients who previously had retinoblastoma (33). In addition, in two of the first three reports on the isolation of the $\mathrm{Rb}$ gene, osteosarcomas were identified in which homozygous internal deletions of the $\mathrm{Rb}$ gene had occurred $(12,14)$. The first case was an individual who had no previous history of retinoblastoma (12) whereas the second case was a patient who had retinoblastoma (14). These results provided the scientific evidence that loss of $\mathrm{Rb}$ function was an important factor in the development of certain osteosarcomas. Subsequently, many additional reports have found abnormalities of the $R b$ gene in osteosarcomas (15-18).

Other tumor types frequently seen as second malignancies in patients with the hereditary form of retinoblastoma, namely specific soft tissue sarcomas, have been reported to have $\mathbf{R b}$ mutations. This includes a total $\mathrm{Rb}$ deletion in a leiomyosarcoma and three malignant fibrous histiocytomas $(16,19)$ as well as $5^{\prime}$ deletions in an undifferentiated sarcoma, a lymphosarcoma, and an unclassified sarcoma $(16,19)$. An internal deletion also has been reported in a fibrosarcoma cell line (20). Therefore, similar to osteosarcoma, loss of function of the $\mathrm{Rb}$ gene may be critical to the initiation and/or progression of specific types of soft tissue sarcomas or subgroups within these tumor types.

Tumors usually not associated with the predisposition to develop retinoblastoma have $R b$ gene changes

Although the tumors described above have provided important information concerning the retinoblastoma gene which in turn may be critical to understanding essential mechanisms involved in the development of human malignancies in general, they do not represent particularly common human cancers. More recently, several common malignancies including those of the breast, lung, and bladder have been reported to have $\mathrm{Rb}$ mutations. The first study of $\mathrm{Rb}$ changes in tumors usually not associated with the development of retinoblastoma was that of SCLC. Structural changes in the Rb gene were seen in a primary SCLC and four SCLC cell lines as well as a pulmonary carcinoid cell line (23). Moreover, the absence of $\mathrm{Rb}$ transcripts were noted in $60 \%$ of the SCLC lines as well as $75 \%$ of the pulmonary carcinoid cell lines (23). Of particular importance was the fact that $5^{\prime}$ and $3^{\prime}$ structural abnormalities 
as well as internal deletions within the $\mathbf{R b}$ gene were documented (23). In a separate paper by other investigators, all the SCLC cell lines examined were shown to have an absence of the $\mathrm{Rb}$ protein (24). These studies provided the basis for concluding that the loss of $\mathrm{Rb}$ function is important in the development of SCLC.

In the reports on SCLC mentioned above, a large cell carcinoma of the lung and an adenocarcinoma of the lung were also found to have no $R b$ protein (24). In addition, the loss of $R b$ mRNA was documented in another large cell carcinoma and an adenocarcinoma of the lung (23). Although these data were obtained on cell lines only, it provided the initial data suggesting that the $\mathrm{Rb}$ gene could be involved in more common lung cancers than SCLC. This appears to be the case based on a collaborative study we have recently completed with Drs. Peter Reissman and Dennis Slamon and the Lung Cancer Study Group. Out of 160 primary non-SCLCs, 18 were found to have abnormal Rb mRNA expression (Reissman, P. T., R. Takahashi, W. F. Benedict, and D. J. Slamon, manuscript submitted for publication). Further studies are necessary to determine what the actual incidence of $\mathrm{Rb}$ loss is in common lung cancers. This analysis will likely be done at the protein level in which single tumor cells in primary tumor will be analyzed as discussed below. However, these results already indicate that the $\mathrm{Rb}$ gene is involved in a considerable percentage of lung cancers. It should also be mentioned again that although lung malignancies have not been associated with the development of retinoblastoma, relatives of patients with hereditary retinoblastoma were reported recently to have a statistically significant higher incidence of lung cancer (26).

The breast is also the most frequent sight of malignancy for females in a large number of countries. Therefore, the finding that $25 \%$ of the breast tumor cell lines initially examined as well as $7 \%$ of primary tumors had $\mathbf{R b}$ abnormalities at the DNA level could be particularly significant (21). Such structural changes included homozygous internal or total deletions resulting in either an absence or truncation of the $R b$ transcript (21). Breast cancer cell lines examined at the $\mathrm{Rb}$ protein level have also been found to be missing Rb protein (22). However, in another collaborative study with Drs. Reissman and Slamon, we could detect structural abnormalities within the $\mathrm{Rb}$ gene in only one of over 100 randomly chosen primary breast tumors (Reissman, P. T., R. Takahashi, W. F. Benedict, and D. J. Slamon, manuscript in preparation). The fact that we were unable to document additional tumors with $\mathrm{Rb}$ changes could be related to the fact that the normal stromal tissue is frequently found in considerable abundance in such tumor specimens. Another possibility is that the $\mathrm{Rb}$ gene is important in the progression of the disease rather than its initiation and therefore a mixed population of tumor cells could be present, some which have normal $\mathrm{Rb}$ expression and others which do not. In this latter case, although tumor cells would be present which lost $\mathrm{Rb}$ function, they might not be detected by DNA or RNA blot analysis of the tumor tissue.

Bladder cancer is another common malignancy in which $\mathrm{Rb}$ gene loss may participate. Although this cancer has not been among those tumors frequently associated with the development of retinoblastoma, it has also been reported that relatives of retinoblastoma patients have a higher incidence of this malignancy than the normal population (26). Therefore, it may not be unexpected that not only have changes within the $\mathrm{Rb}$ gene been recorded in bladder cancer cell lines (25), but they may be as frequent in primary bladder cancer (T'Ang, A., et al., manuscript in preparation) as has been reported for breast cancer (21). As additional human malignancies are examined for the status of the $\mathrm{Rb}$ gene, the likelihood is high that at least some of these tumors will be found to have lost $R b$ function. It will then be critical to determine whether this change is etiologically related to the development of this specific cancer, i.e., initiation or whether it is important instead in the progression of the disease. It is our hope that the approach that we shall now discuss will enable us to distinguish between these two possibilities.

\section{Is the loss of $R b$ function related to initiation or progression of specific cancers?}

It is obvious that $R b$ mutations resulting in the loss of $R b$ function are important changes in the development of many human malignancies. Although it is likely that these mutations play a role in the initiation of retinoblastoma and other tumors that develop as second malignancies in individuals with the hereditary form of retinoblastoma, the potentially more critical issue is to determine the significance of these mutations in some of the more common human malignancies, including those of the lung and breast. The key issue to us is whether the
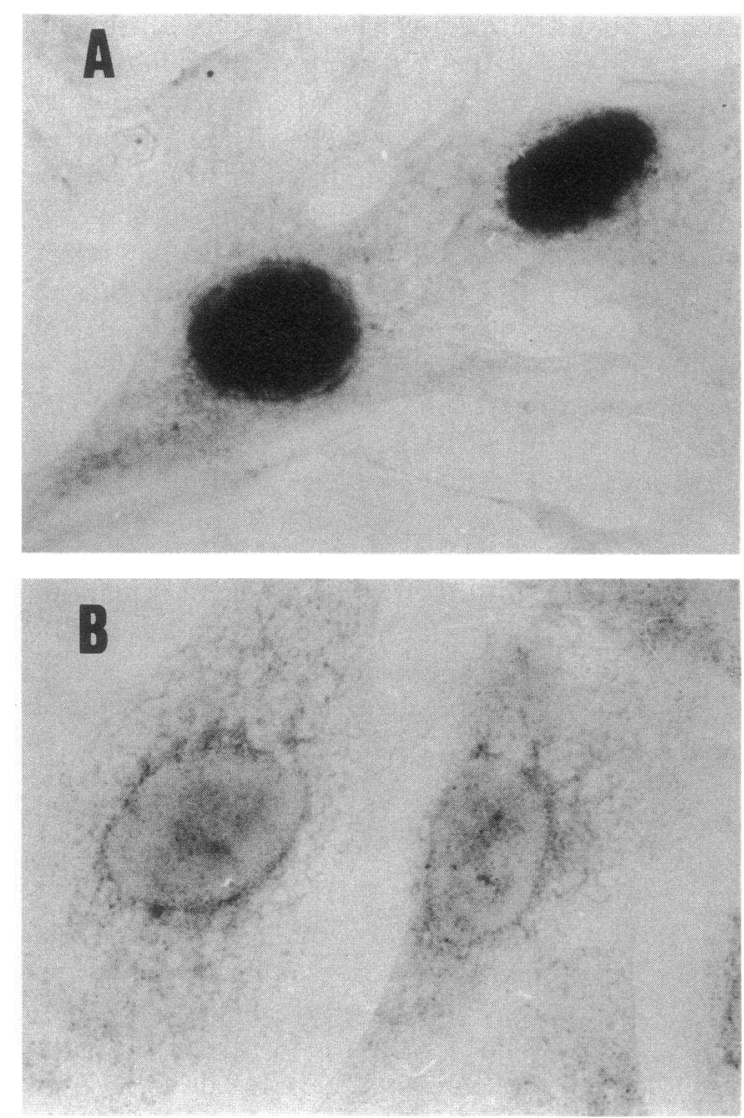

Figure 1. Staining of the $\mathrm{Rb}$ protein at the single-cell level. Positive $\mathrm{Rb}$ nuclear staining is seen for the normal human fibroblasts, WI-38 $(A)$, whereas no nuclear staining is present in the fibrosarcoma cells, Hs 913T $(B)$, which has a large homozygous deletion within the Rb gene (20) resulting in the loss of $R b$ transcripts and $R b$ gene products. The Rb antibody, WL-1 (18), and a second antibody conjugated with alkaline phosphatase were used for the immunostaining procedures. 
loss of $\mathrm{Rb}$ gene function is related to its role in the initiation of a tumor vs. the possibility that such loss is associated with tumor progression. We believe that the most reasonable approach to distinguish between these two possibilities may be to examine the status of the $R b$ protein at the single-cell level in each tumor type. This will require the use of immunohistochemical methods which we believe are now available to perform such studies.

One of the reagents likely to be successfully used for this analysis is the purified high-affinity $\mathrm{Rb}$ polyclonal antibody that we have recently described (18). This $\mathrm{Rb}$ antibody first allowed us to study the normal $\mathrm{Rb}$ protein pattern using both immunoprecipitation and Western immunoblotting (18). Subsequently, we have been able to utilize these antibodies not only to confirm the nuclear staining of the Rb protein (34), but also to extend the findings of previous publications. A typical staining pattern found in Rb-positive cells compared to $\mathrm{Rb}$ negative cells from the same embryonic origin is illustrated in Fig. 1. Clear nuclear staining is seen in the Rb-positive normal WI-38 fibroblasts (Fig. 1A), whereas an absence of nuclear staining is apparent in fibrosarcoma cells in which the $\mathbf{R b}$ protein is missing (Fig. $1 B$ ). More recently, techniques have been developed using these same $\mathrm{Rb}$ antibodies to document the presence of the $\mathrm{Rb}$ protein at the single cell level in frozen tumor tissue (Xu, H.-J., S.-X. Hu, M. Rieger, and W. F. Benedict, manuscript submitted for publication).

Therefore, it now should be possible to examine various primary human tumors at the single-cell level and to determine whether there are any Rb-positive tumor cells present. If no $\mathrm{Rb}$-positive cells are identified, as is the case in primary retinoblastomas (Xu, H.-J., S.-X. Hu, and W. F. Benedict, manuscript in preparation), this would indicate that the gene was likely causally related to the initiation of the tumor (Fig. 2,
Cancer 1 ). In contrast, if the loss of $\mathrm{Rb}$ protein can only be primarily observed in focal areas within a tumor or in a metastasis from this primary tumor (Fig. 2, Cancer 2), such findings would suggest that the loss of $R b$ function is involved in tumor progression rather than in its development. This might be the case for breast cancer if an initial study can be confirmed which indicated that certain breast tumors contain a few Rb-positive tumor cells, whereas the majority of tumor cells are $\mathbf{R b}$ negative (35). Should an Rb mutation be associated with tumor progression, it would then be most important to determine if there is a poorer prognosis and/or therapeutic response in patients having a tumor in which a signifcant portion of their cancer cells are $\mathrm{Rb}$ negative compared to those individuals with malignancies of the same tissue type which are $\mathrm{Rb}$ positive. If such a correlation could be found, it obviously would have considerable clinical value.

It should be mentioned at this point that, even if all tumor cells in a given cancer are missing the $\mathrm{Rb}$ protein, indicating that the $\mathbf{R b}$ gene functional loss is involved in the initiation of this particular tumor, it is likely that there will be several other genes which are also factors in the development of this specific malignancy. The one exception to this generality may be retinoblastoma (Fig. 3). As mentioned above, we have found in our initial study that all tumor cells from primary retinoblastomas examined to date which do not have a truncated $\mathbf{R b}$ protein are $\mathrm{Rb}$ negative (Xu, H.-J., S. X. Hu, and W. F. Benedict, manuscript in preparation). In contrast, the development of certain malignancies such as osteosarcoma likely requires the involvement of additional cancer genes. Some of these genes may in fact be similar to the $R b$ gene in that loss of function could be the basis for their role in tumor formation.

One candidate gene that, in addition to the $\mathrm{Rb}$ gene, might be involved in the development of specific tumors is the p53

\section{Constitutional Cells}

\section{Tumor Initiation Primary Tumor}

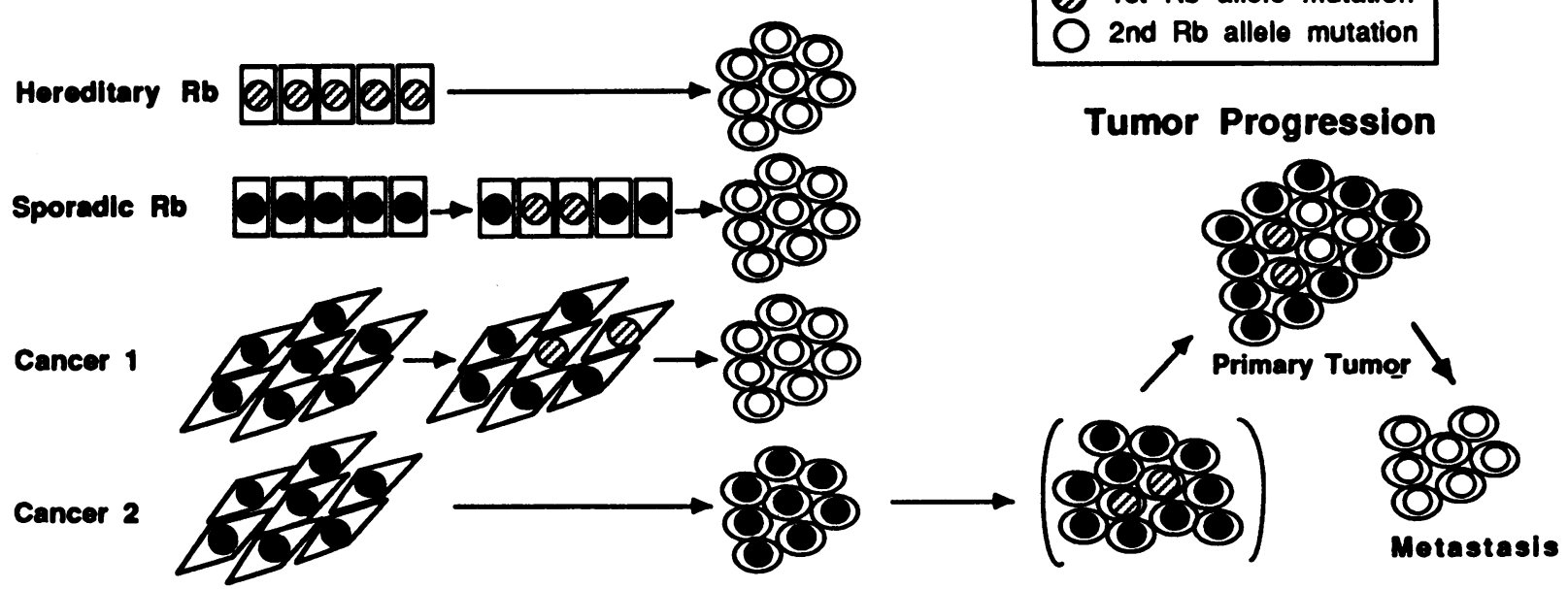

Figure 2. Schematic representation of the expected $\mathrm{Rb}$ staining pattern in individual tumor cells depending on whether the loss of $\mathrm{Rb}$ function is related to the initiation vs. the progression of a specific malignancy. In primary retinoblastoma all tumor cells should be negatively stained $(\mathrm{O})$ since the loss of $\mathrm{Rb}$ function is causally involved in tumor initiation (see text). Rb protein would also be missing in every cell in other malignancies in which $\mathrm{Rb}$ functional loss is associated with the tumor development (Cancer 1). In contrast, cancers where the loss of $\mathrm{Rb}$ function has a role in tumor progression rather than in its initiation, one would expect to find only a portion of the primary tumor in which every cell was missing the $\mathrm{Rb}$ protein or malignancies where the total absence of the $\mathrm{Rb}$ protein could only be documented in metastasis (Cancer 2$)$. The intermediate cell shown in parenthesis would be required in such a scenario, although cells in which functional Rb loss occurs in only one allele $(\oslash)$ cannot be distinguished from cells containing two normal Rb alleles at the protein level $(\bullet)$. 


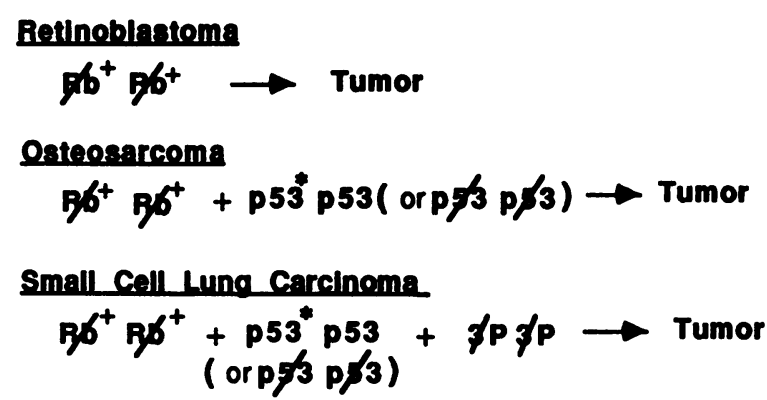

Figure 3. Role of $\mathbf{R b}$ functional loss in the initiation of different tumor types. Retinoblastoma may be unique in that functional loss of both $\mathrm{Rb}$ alleles could be sufficient for malignant development. In osteosarcoma a mutation of one p53 allele $\left(^{*}\right)$ could indirectly inactivate the wild-type $\mathrm{p} 53$ protein encoded for by the remaining normal p53 allele (36) or both $\mathrm{p} 53$ alleles could be deleted. In either case a loss of $\mathrm{p} 53$ would occur. Therefore, $\mathrm{p} 53$ could represent a second "suppressor" gene involved in the development of osteosarcoma (37). Finally, a third recessive "suppressor" gene located on chromosome $3 p$ is also likely to be associated with tumor initiation of SCLC (38).

gene which is located on chromosome 17. Structural changes within p53 have been reported for osteosarcoma resulting in the loss of p53 transcript (37). Moreover, abnormalities in p53 including total homozygous deletions have recently been found in SCLCs (39). It should also be noted that deletions in chromosome $3 p$ have been frequently seen in SCLCs (38), which suggests that a minimum of three "suppressor" genes could be involved in the initiation of this tumor type (Fig. 3). In fact, it is likely that many of the more common human cancers such as those of the lung and breast require additional changes that include not only genetic lesions which result in the loss of gene function, but also mutations which yield an altered gene product.

In conclusion, it should be apparent that the loss of $\mathbf{R b}$ function has a central role in the initiation and/or progression of a significant number of human cancers. The determination of the precise involvement of the Rb gene in these tumors will be a major future task. These studies will include many disciplines as well as approaches. One will need to examine the presence or absence of the $\mathbf{R b}$ protein at the single-cell level in various tumors and correlate these findings with prognosis and/or therapeutic response as mentioned above. In addition, examination of the $\mathbf{R b}$ phosphorylation changes that occur during the cell cycle and the kinases involved in its phosphorylation have already provided interesting leads to the function of the Rb gene (40) and future studies in this area should be equally informative. Moreover, much excitement has recently been generated by the observation that transforming proteins of DNA viruses, in particular those of the adenovirus, polyomavirus, and papillomavirus classes bind to the $\mathrm{Rb}$ protein(s) (40). Mutations introduced into these viruses which inhibit the binding of these specific transforming proteins to $\mathrm{Rb}$ also reduce or block the transforming capacity of the virus (40). These results imply that DNA viruses transform by blocking the function of the $\mathrm{Rb}$ at the protein level which is analogous to the loss of $\mathbf{R b}$ function by genetic deletion. Such binding could aid in the transformation process at several levels in the cell cycle including the movement of cells from the $G_{0}$ state into the proliferative pool or the inhibition of differentiation
(40). It can be expected that studies that continue to examine the interaction of DNA oncoproteins with the Rb protein(s) will provide important leads to the $\mathrm{Rb}$ function and its role in the cell cycle.

A final major goal of future research in the $\mathrm{Rb}$ field will be to determine the result of adding a normal chromosome 13 and the $\mathrm{Rb}$ gene itself back into the various human tumor types in which loss of $R b$ function has been shown to occur. If tumor initiation could be inhibited in each case by this manipulation, it would be a major finding and provide the impetus to pursue new diagnostic and therapeutic approaches for many of the most common human malignancies. Whatever the results of these studies, however, one can be assured that life will not be dull or competition lacking for those who are now or later become involved in unraveling the function of the $\mathrm{Rb}$ gene and its role in human cancers!

\section{Acknowledgments}

Much of the work discussed has been supported by grants EY02715 and EY06195 from the National Eye Institute and grants from Triton Biosciences, Inc. and the Retina Research Foundation. This work was done in conjunction with the Clayton Foundation for Research.

\section{References}

1. Murphree, A. L., and W. F. Benedict. 1984. Retinoblastoma: clues for human oncogenesis. Science(Wash. DC). 223:1028-1033.

2. Knudson, A. G. 1985. Hereditary cancer, oncogenes, and antioncogenes. Cancer Res. 45:1437-1443.

3. Knudson, A. G. 1971. Mutation and cancer: statistical study of retinoblastoma. Proc. Natl. Acad. Sci. USA. 68:820-823.

4. Yunis, J. J., and N. Ramsay. 1978. Retinoblastoma and subband deletion of chromosome 13. Am. J. Dis. Child. 132:161-163.

5. Sparkes, R. S., A. L. Murphree, R. W. Lingua, M. C. Sparkes, L. L. Field, S. J. Funderburk, and W. F. Benedict. 1983. Gene for hereditary retinoblastoma assigned to human chromosome 13 by linkage to esterase D. Science (Wash. DC). 219:917-979.

6. Benedict, W. F., A. Banerjee, C. Mark, and A. L. Murphree. 1983. Non-random chromosomal changes in direct preparations of primary retinoblastoma. Cancer Genet. Cytogenet. 10:311-333.

7. Balaban, G., F. Gilbert, W. Nichols, A. T. Meadows, and J. Shields. Abnormalities of chromsome \#13 in retinoblastomas from individuals with normal constitutional karyotypes. Cancer Genet. $C y$ togenet. 6:213-221.

8. Cavenee, W. K., T. P. Dryja, R. A. Phillips, W. F. Benedict, R. Godbout, B. L. Gallie, A. L. Murphree, L. C. Strong, and R. L. White. 1983. Expression of recessive alleles by chromosomal mechanisms in retinoblastoma. Nature (Lond.). 305:779-784.

9. Dryja, T. P., W. Cavenee, R. White, J. M. Rapaport, R. Petersen, D. M. Albert, and G. A. P. Bruns. 1984. Homozygosity of chromosome 13 in retinoblastoma. N. Engl. J. Med. 310:550-553.

10. Benedict, W. F., E. S. Srivatson, C. Mark, A. Banerjee, R. S. Sparkes, and A. L. Murphree. 1987. Complete or partial homozygosity of chromosome 13 in primary retinoblastoma. Cancer Res. 47:41894191.

11. Abramson, D. H., R. M. Ellsworth, F. D. Kitchin, and G. Tung. 1984. Second monocular tumors in retinoblastoma survivors. Ophthalmology. 91:1351-1355.

12. Friend, S. H., R. Bernards, S. Rogeli, R. A. Weinberg, J. M. Rapaport, D. M. Albert, and T. P. Dryja. 1986. A human DNA segment with properties of the gene that predisposes to retinoblastoma and esteosarcoma. Nature (Lond.). 323:643-646.

13. Lee, W.-H., R. Bookstein, F. Hong, L.-J. Young, J.-Y. Shew, and Y. H. P. Lee. 1987. Human retinoblastoma susceptibility gene: cloning, identification and sequence. Science (Wash. DC). 235:13941399. 
14. Fung, Y. K. T., A. L. Murphree, A. T'Ang, J. Qian, S. H. Hinrichs, and W. F. Benedict. 1987. Structural evidence for the authenticity of the human retinoblastoma gene. Science (Wash. DC). 236:1657-1661

15. Weichselbaum, R., M. Beckett, and A. Diamond. 1988. Some retinoblastomas, osteosarcomas, and soft tissue sarcomas may share a common etiology. Proc. Natl. Acad. Sci. USA. 85:2106-2109.

16. Reissman, P. T., M. A. Simon, W.-H. Lee, and D. J. Slamon. 1989. Studies of the retinoblastoma gene in human sarcomas. Oncogene. 4:839-843.

17. Toguchida, J., K. Ishizaki, M. S. Sasaki, M. Ikenaga, M. Sugimoto, Y. Kotoura, and T. Yamamuro. 1988. Chromosomal reorganization for the expression of recessive mutation of retinoblastoma susceptibility gene in the development of osteosarcoma. Cancer Res. 48:3939-3943.

18. Xu, H.-J., S.-X. Hu, T. Hashimoto, R. Takahashi, and W. F. Benedict. 1989. The retinoblastoma susceptibility gene product: a characteristic pattern in normal cells and abnormal expression in malignant cells. Oncogene. 4:807-812.

19. Friend, S. H., J. M. Horowitz, M. R. Gerber, X. F. Wang, E. Bogenmann, F. P. Li, and R. A. Weinberg. 1987. Deletions of a DNA sequence in retinoblastomas and mesenchymal tumors: organization of the sequence and its encoded protein. Proc. Natl. Acad. Sci. USA. 84:9059-9063.

20. Benedict, W. F., Y.-K. T. Fung. 1988. Structural and expressional changes of the retinoblastoma susceptibility gene in various human cancers. In Proceedings of the Retina Research Foundation Symposium, Volume 1. D. M.-K. Lam, editor. Portfolio Publishing Co, The Woodlands, TX. 108-112.

21. T'Ang, A., J. M. Varley, S. Chakraborty, A. L. Murphree, and Y.-K. T. Fung. 1988. Structural rearrangement of the retinoblastoma gene in human breast carcinoma. Science (Wash. DC). 242:263-266.

22. Lee, E. Y. H. P., H. To, J. Y. Shew, R. Bookstein, P. Scully, and W. H. Lee. 1988b. Inactivation of the retinoblastoma susceptibility gene in human breast cancers. Science (Wash. DC). 241:218-221.

23. Harbour, J. W., S.-L. Li, J. Whang-Peng, A. F. Gazdar, J. D. Minna, and F. J. Kaye. 1988. Abnormalities in structure and expression of the human retinoblastoma gene in SCLC. Science (Wash. DC). 241:353-357.

24. Yokota, J., T. Akiyama, Y. K. T. Fung, W. F. Benedict, Y. Namba, M. Hanaoka, M. Wada, T. Terasaki, Y. Shimosato, T. Sugimura, et al. 1988. Altered expression of the retinoblastoma (RB) gene in small-cell carcinoma of the lung. Oncogene. 3:471-475.

25. Horowitz, J. M., D. W. Yandell, S.-H. Park, S. Canning, P. Whyte, K. J. Buchkovich, E. Harlow, R. A. Weinberg, and T. P. Dryja. 1989. Point mutational inactivation of the retinoblastoma antioncogene. Science (Wash. DC). 243:937-940.

26. Sanders, B. M., M. Jay, G. J. Draper, and E. M. Roberts. 1989. Non-ocular cancer in relatives of retinoblastoma patients. $B r$. $J$. Cancer. 60:358-365.

27. Lalande, M., T. P. Fryja, R. R. Schreck, J. Shipley, A. Flint, and S. A. Latt. 1984. Isolation of human chromosome 13-specific DNA sequences cloned from flow sorted chromosomes and potentially linked to the retinoblastoma locus. Cancer Genet. Cytogenet. 13:283295.

28. Dryja, T., J. M. Rapaport, J. M. Joyce, and R. A. Petersen. 1986. Molecular detection of deletions involving band 14q of chromosome 13 in retinoblastomas. Proc. Natl. Acad. Sci. USA. 83:73917394.

29. Canning, S., and T. P. Dryja. 1989. Short, direct repeats at the breakpoints of deletions of the retinoblastoma gene. Proc. Natl. Acad. Sci. USA. 86:5044-5048.

30. Yandell, D. W., T. A. Campbell, S. H. Dayton, R. Petersen, D. Walton, J. B. Little, A. McConkie-Rosell, E. G. Buckley, and T. P. Dryja. 1989. Oncogenic point mutations in the human retinoblastoma gene: their application to genetic counseling. N. Engl. J. Med. 321:1689-1695.

31. Dunn, J. M., R. A. Phillips, A. J. Becker, and B. L. Gallie. 1988 Identification of germline and somatic mutations affecting the retinoblastoma gene. Science (Wash. DC). 241:1797-1800.

32. Huang, H.-J. S., J.-K. Yee, J.-Y. Shew, P.-L. Chen, R. Bookstein, T. Friedmann, E. Y.-H. P. Lee, and W.-H. Lee. 1988. Suppression of the neoplastic phenotype by replacement of the RB gene in human cancer cells. Science (Wash. DC). 242:1563-1566.

33. Hansen, M. F., A., Koufos, B. L. Gallie, R. A. Phillips, Ø. Fødstad, A. Brogger, T. Gedde-Dahl, and W. K. Cavenee. 1985. Osteosarcoma and retinoblastoma: a shared chromosomal mechanism revealing recessive predisposition. Proc. Natl. Acad. Sci. USA. 82:6216-6220.

34. Lee, W.-H., J.-Y. Shew, F. D. Hong, T. W. Sery, L. A. Donoso, L. J. Young, R. Bookstein, and E. Y. Lee. 1987. The retinoblastoma susceptibility gene encodes a nuclear phosphoprotein associated with DNA binding activity. Nature (Lond.). 329:642-645.

35. Varley, J. M., J. Armour, J. E. Swallow, A. J. Jeffreys, B. A. J. Ponder, A. T'Ang, Y.-K. T. Fung, W. J. Brammar, and R. A. Walker. 1989. The retinoblastoma gene is frequently altered leading to loss of expression in primary breast tumors. Oncogene. 4:725-729.

36. Finlay, C. A., P. W. Hinds, and A. J. Levine. 1989. The p53 proto-oncogene can act as a suppressor of transformation. Cell. 57:1083-1093.

37. Masuda, H., C. Miller, H. P. Koeffler, H. Battifora, and M. J. Cline. 1987. Rearrangement of the p53 gene in human osteogenic sarcomas. Proc. Natl. Acad. Sci. USA. 84:7716-7719.

38. Whang-Peng, J., P. A. Bunn, C. S. Kao-Shan, E. C. Lee, D. N. Carney, A. Gazdar, and J. D. Minna. 1982. A non-random chromosomal abnormality, del 3p(14-23), in human small cell lung cancer (SCLC). Cancer Genet. Cytogenet. 6:119-134.

39. Takahashi, T., M. M. Nau, I. Chiba, M. J. Birrer, R. K. Rosenberg, M. Vinocour, M. Levitt, H. Pass, A. F. Gazdar, and J. D. Minna. 1989. p53: a frequent target for genetic abnormalities in lung cancer. Science (Wash. DC). 246:491-494.

40. Cooper, J. A., and P. Whyte. 1989. RB and the cell cycle: entrance or exit? Cell. 58:1009-1011. 